\title{
A multi-period and multi-product optimizer for cooperative supply chains
}

\author{
M. Sepehri ${ }^{\star}$ \\ Graduate School of Management and Economics \\ Sharif University of Technology, Tehran, Iran \\ sepehri@sharif.edu \\ K. Fayazbakhsh \\ Department of Computer Engineering and IT \\ Amirkabir University of Technology, Tehran, Iran \\ fayazbakhsh@aut.ac.ir
}

Received August 2010

\begin{abstract}
Members in a traditional supply chain compete to reduce their individual costs. But total cost is minimized in a cooperative, or a corporate managed, supply chain. A lower average cost and a lower cost variation are achieved by cooperative individual members in the long-run. The problem is formulated and solved as an integrated flow network. Previous research is expanded to include multi-period and multi-product cooperative supply chain with possibility of holding inventory in a multi-stage, multi-member setup. A Cooperative Supply Optimizer System (CSOS), a softwarebased coordination mechanism, is developed for large chains. It gathers operational information from members of the supply chain, and then guides them on ordering decisions for a minimum cost of the entire supply chain. Simulation results indicate an approximately $26 \%$ reduction in total supply chain costs, utilizing this formulation over a competitive setup. As the holding costs increase, the problem decomposes into single period (Just-in-time) again. The disturbing bullwhip effect disappears in cooperative supply chains.
\end{abstract}

*To whom all correspondence should be addressed.

\section{Introduction}

Supplier management is a critical success factor in achieving sustainable competitive advantage for today's corporations (Handfield, et al., 1999; Monczka, Trent \& Handfield, 1998). It is concerned with developing, planning and monitoring company relationships with the current and potential suppliers. Supplier management requires "organizing an optimal flow of high-quality, value-formoney components and materials from a suitable set of suppliers to manufacturing companies to final customers" (Goffin, Szwejczewski \& New, 1997; Wagner, 2000). It should reach beyond the first tier of supplier to help coordinate and reduce the overall costs for the entire supply chain (Cachon, 2003).

A supply chain is "a network of organizations involved, through upstream and downstream linkages, in the different processes and activities that produce value in the form of products and services in the hand of the ultimate customer" (Christopher, 1998). "The coordination and integration of key business activities undertaken by an enterprise, from the procurement of raw materials to the distribution of end products to the customers, are done in the supply chain planning process" (Gupta \& Maranas, 2003). While ebusiness can simplify the communications between the suppliers and customers, many suppliers still find it challenging to provide timely deliveries of goods and services to their customers due to their resource limitations and geographical distances (Chopra \& Meindl, 2003).

Supply chain literature has been developed extensively in the past two decades. But an integrated optimization model is not found to include all aspects of cost and capacity for multi-period, multi-stage and multi-products, which may additionally include customer priority or product inventory. In a cooperative or a corporate supply chain, the overall optimization problem is not yet addressed (Fayazbakhsh \& Sepehri, 2010). Existing literature assumes a limited number of members in the supply chain with usually a single product or a single period, and mostly provides solutions for competitive supply chains. Furthermore, such optimization models have not been implemented in real cases, nor have utilized an integrated real-time mechanism using advances in electronic procurement. In fact, most real-time supplier management systems in practice lack optimization engines or dynamic capabilities for re-assigning supply allocations (Cusumano \& Takeishi, 1991).

The model here considers the general case of multi-member, multi-stage, multi-product, multi-period cooperative supply chain with possibility of holding inventories. The main idea 
in the proposed mechanism is to formulate the supply chain as a flow network, and then solve the corresponding integrated linear programming model. A Cooperative Supply Optimizer System (CSOS), which may actually be an electronic hub (e-hub), is developed and implemented. CSOS gathers and processes necessary information on capacities and operation costs from the supply chain members. Then it guides the chain members on ordering decisions, therefore providing a minimum overall cost for the entire supply chain. Without such concept and mechanism, members will make decisions on their order quantities based on their local and accessible information, resulting in non-optimal performance of the entire supply chain and higher cost variances for individual members.

Organization of the paper is as follows. The next two sections review the widespread literature on the cooperative supply chains and coordination of such supply chains, limited to the relevant publications to scope of this research. Section four is devoted to the problem definition and problem formulation. It reviews the assumptions associated with problem definition, flow networks, and the coordination mechanism. The next section covers evaluation of the model with assessment of its performance, just-intime and bullwhip effects. The last section is the conclusions and an extensive reference section.

\section{Cooperative supply chains}

Two opposite models of supplier management, cooperative and non-cooperative, have emerged from both practice and academic research (Dyer, Cho \& Chu, 1998). The traditional, "more common arm's length, approach to supplier management is characterized by the buying firm's efforts to avoid dependence on suppliers and to maximize bargaining power" (Porter, 1980). The metaphor of the firm as an "island in a sea of market relationships" (Richardson, 1993) captures fully the distinctive feature of this standpoint. In contrast to the competitive/non-cooperative approach, many firms work closely with their suppliers, as partners, integrating and developing them for the long-term. Various studies showed that such strategy leads to a better information sharing and, as a result, constantly improving quality, product development cycle, and a highly efficient governance mechanism that minimizes transaction costs (Cusumano \& Takeishi, 1991; Dyer, 1996; Szwejczewski et al., 2001).

With the spread of cooperative approach, the business world's view changed thoroughly giving rise to a network of strategic interdependence among firms pursuing convergent interests and deriving mutual benefits (Contractor \& Lorange, 1988). This alternative perspective, as a reaction to the competitive approach partly spreading out initially from Japanese JIT purchasing (Sepehri, 1986). It emphasizes the empowerment of a collaborative network. The economic interest to keep on with the current relationship rather than enter new relationships comes from reputational concerns (Hill, 1990). This keeps the partners aligned to the norms of trustworthy behavior (Brusco, 1996; Griesinger, 1990). Zipkin (2000) compared competitive and cooperative inventory policies in a two-stage supply chain (Cachon \&
Zipkin, 1999) to show competition reduces overall efficiency.

Supply networks are widely known and publicized phenomena, especially in high-tech sectors. Companies such as Microsoft or Genentech pursue their network strategies through research and development joint ventures, crosslicensing or strategic alliances (Lorenzoni \& Baden-Fuller, 1995). Networks are not only important for small firms that need to interact with their peers to supplement their limited resources, but they are fundamental for large companies too. For instance, multinational companies in steel, paper and automotive industries interact tightly with their suppliers, sub-suppliers, distributors, and customers to develop new technologies or to increase efficiency (Koka \& Prescott, 2002). There are many examples of large firms from several sectors that relied strongly on supply networks for their rapid growth, such as Apple Computers, Benetton, Toyota, Corning, McDonald's (Powell, 1987). In Brazil, outsourcing has a high significance, as material costs often make up more than $60 \%$ share of the total costs. Effective supplier management is regarded in Brazil as crucial to differentiate oneself from competitors in the long run (Corrêa \& De Miranda, 1998).

\section{Corporate-managed supply}

Outsourcing has become a hot topic for many companies recently. They are pushing some of their processes onto the outside suppliers, while keeping control over the timing and mix of flow from each link (Lynch, 2006). Although each supplier is a distinct and independent business, the clients persist in a complete or high control over the timing and mix of their required supply. A focus on opportunities, to add value, provides a basis for valid corporate outsourcing strategy, and leverages out the distinctive resources possessed by the corporate parent in order to manage the added value (Campbell, Devine \& Young, 1993). Many suppliers therefore enter into partnership or alliance agreements so that they can share the benefits of serving customers better in a particular market (Lynch, 2006).

Traditionally, the role of a Corporate Headquarter (CHQ) was limited to monitoring and working on incentive issues. Such role may be expanded to exploit economies of scope and other synergies, to build up larger internal capital markets, and to direct mix of activities within each unit (Collis \& Montgomery, 2004). Its strategies focus on identifying the purpose of the whole organization and the plans to achieve that purpose amongst the business units (Lynch, 2006). CHQ, or the parent unit, can also help the other units expand their size and scope of activities in, for example, product extensions or globalization (Lynch, 2006). In a multi-business company, each business needs to have its own strategy to succeed in its particular product market. Nonetheless, the corporate strategy must be more than simply aggregating business strategies (De Wit \& Meyer, 2004). Corporate strategies should facilitate the coordination of organizational actions and their interactions (Goold, Campbell \& Alexander, 1994).

Such coordination can result on lower overall costs shared by all business units. Proff (2006) developed a research 
concept to assess the consistency of corporate strategies. The research hypothesis, that return on equity (ROE) increases with an increase in consistency between the corporate and lower-level business strategies. It was significantly confirmed by an empirical investigation of the corporate strategies, using a sample of the 35 largest German diversified firms (Proff, 2006). Corporate strategists interested in such integration, focus on creating the organizational circumstances under which such selforganization can take place (Goold, Campbell \& Alexander, 1998).

A case in point is IKEA in Southern Sweden. It has grown to become the world's largest furniture retailer. During expansion in the 1960s, IKEA laid the groundwork for its purchasing strategy, relying on long-term relationships with selected suppliers as external sources for its offerings (Baraldi, 2008). IKEA designs and purchases products that entail low production and transportation costs. It carefully takes into account all the activities performed in the supplier network, from raw materials to customer homes. IKEA performs only a few of these activities internally. It uses intensively its relationships with suppliers to combine its internal and their external resources (Baraldi, 2008).

\section{Supply chain coordination}

Coordination among members and stages or, in other words, among a network of buyers and sellers is a major challenge in cooperative supply chains ( $\mathrm{Li} \&$ Wang, 2007). This generated much interest in the past several decades. As the actual number of businesses related to supply, manufacturing and distribution of products increase in practice, the coordination issue becomes immensely complicated (Cachon \& Lariviere, 2005). In real-world situations, most firms only pay attention to optimizing separately their production and distribution planning decisions. However, these local decisions limit possible improvements in overall decision effectiveness and efficiency.

Supply chain coordination includes contract management, negotiation, information sharing, quantity-discounts, revenue-sharing, cooperative advertising, promotional rebate and franchising, quantity-price-discounts, and buyback contracts (Cachon \& Lariviere, 2005; Shin \& Benton, 2007; Liu, Zhang \& Zhao, 2005; Fugate, Sahin \& Mentzer, 2006). Li and Wang (2007) provided a survey of traditional coordination mechanisms for supply networks taking an inventory control approach. Cachon provided a study of coordination contracts (Cachon, 2003) to show increase in the number of members in supply networks transform traditional contracts into inefficient coordination mechanisms. Lee and Whang (2000) described inventory, sales, demand forecast, order status, and production schedule as different types of information sharing. They as well as Cachon and Fisher (2000) clearly show the significance of information sharing in a two-level supply chain. However, lack of information sharing aggravates the incurred cost in a supply chain with multiple members in several stages (Lee, Padmanabhan \& Wang, 1997b; Metters, 1997). Managing and sharing business information may include customer relationship management (CRM), supplier relationship management (SRM), e-marketplaces and echains (Chopra \& Meindl, 2003; Kelle \& Akbulut, 2005; Grieger, 2003; Eng, 2004; Bourland, Powell \& Pyke, 1996; Singh, Salam \& Iyer, 2005).

Dudek and Stadtler (2005) studied a two-member supply chain. By defining members' mathematical operational model, they proposed a negotiation mechanism to reduce total costs. Chen, et al. (1999) proposed a flexible negotiation-based multi-agent system where new members can join in the supply chain or its current members may leave. Fox, Chionglo and Barbuceanu, (1993) developed a high-level framework for supply chain functions, with the idea of encapsulating these functions in corresponding software agents. Consequently, Fox, Barbuceanu and Teigen. (2000) presented a general approach to supply chain management operations covering planning and execution of actions with different types of software agents.

A significant question is that while members of supply chains do not trust each other completely, why should they accept to share their own strategically important information via such coordination systems? Sahin and Robinson (2002) provided a literature review in product flow and information sharing in supply chains, indicating an advantage based on the degree of information sharing. Li (2002) investigated the incentives for members in a two-level supply chain, with one manufacturer and several retailers sharing information horizontally. He concluded that voluntary information sharing is not rationally preferable, and therefore examines conditions under which information can be traded. Thus, it may be essential to restrict unplanned shared information as much as possible.

Fazel Zarandi et al. (2008) attempted to provide an agentbased architecture based on fuzzy logic to create a responsive and cooperative supply chain. Ding and Chen (2008) considered using negotiation in return policy to coordinate a three-stage supply chain, with a single member in each stage. Fink (2004) proposed using a mediator software agent to conduct a bilateral negotiation process until both firms accept a contract. Lee et al. (1997b), developed an stochastic, periodic-review, order-up-to inventory model to manage a procedure for process localization in the supply chain. They proposed an approach to operational and delivery processes that consider differences in target market structures (e.g., differences in language, environment, or governments). Cachon and Lariviere (2005) considered a two-stage supply chain including a supplier and a retailer, in which time is divided into an infinite number of discrete periods. Consumer demand at the retailer is stochastic, independent across periods and stationary. The system's optimal solution minimizes the total average cost per period.

Cohen and Lee (1988) developed an aggregate model integrating material control, production and distribution submodels for establishing a requirement policy for materials in every factory in supply chain's production system. Barbarsoglu and Ozgur (1999) developed a mixed-integer mathematical model with a centralized planning to address production and two-echelon distribution decisions simultaneously. A Lagrangean relaxation approach was used 
to decouple the imbedded distribution and production subproblems in solving the resultant large-scale problem. Despite a comprehensive approach to the problem, the issue of several agents' interactions remains unexplored.

Lee and Kim (2002) extended the concept of Byrne and Bakir (1999) to propose a hybrid approach combining analytical and simulation models to solve manufacturingdistribution planning problems involving multi-products and multi-periods in supply chains. Ozdamar and Yazgac (1999) developed an integrated production-distribution model based on the operating system of a multi-national company, producing detergents in a central factory where products were distributed to geographically distant warehouses. A hierarchical planning approach was adopted to make use of medium range aggregate information, and satisfy weekly fluctuating demands with an optimal fleet size.

Gunnarsson and Rönnqvist (2008) considered the integrated planning of production and distribution for a pulp company. Their solution is based on heuristics with a one year planning period and several time periods. The work presented by Almansoori and Shah (2009) was an attempt to design and operate a deterministic, steady-state hydrogen supply chain network using a mathematical modelling approach. The model was developed to consider the availability of energy sources and their logistics, and the variation of hydrogen demand over a long planning horizon leading to phased infrastructure development. The proposed model was formulated as a mixed-integer linear programming.

Using linear programming techniques to formulate and analyze the various supply chain management problems has a long record in the literature. Inventory management and production-distribution planning problems make use of linear programming schemes extensively (Silver, Pyke \& Peterson, 1998; Dogan \& Goetschalckx, 1999; Sarmiento \& Nagi, 1999; Dhaenens-Flipo \& Finke, 2001; Boudiaa \& Prins, 2007; Zipkin, 2000; Chen, 2004). Additionally, designing distribution networks (Chopra, 2003; Tsiakis \& Papageorgiou, 2008; Amiri, 2006), facility location allocation (Daskin, 1995; Langevin \& Riopel, 2005; Meloa, Nickela \& Da Gama, 2006), facility capacity allocation problem (Tayur, Ganeshan \& Magazine, 1998) and the aggregate planning (Chopra \& Meindl, 2003; Gomes da Silva et al., 2004), part of supply chain management decisions, may also use Linear Programming. Mixed Integer programming provides more accurate description of different supply chain problems, but reaching the fast and exact solutions to the problem might be a challenge (Jayaraman \& Pirkul, 2001).

\section{Problem definition}

The supply chain management problem here is a multiperiod cooperative supply chain with multiple members in at least four stages, providing multiple products to the customers. The stages include suppliers, manufacturers, distributors and retailers. Each product is manufactured from a number of basic components or raw materials from the suppliers. A supplier has a limited capacity for providing each basic component. Each manufacturer may produce all products, limited by its production and delivery capacities or decided by its strategies. The distributors, within their capacities, send the products from the manufacturers to the retailers. The retailers sell the products to the customers. Forecasted demand is available for the next several periods, depending on accessibility of forecast. The retailers are assumed to have also exactly forecasted demand information of the next $\mathrm{T}$ periods.

The above definition erases three simplifying assumptions in the current supply chain literature, i.e. limited number of members in supply chain stages, limited number of planning periods, and a single-product. The model here assumes that the sale prices for the components and the products are constant and independent of the chain performance. They are derived from the overall supply and demand in a competitive market and are not controlled significantly by individual members. The problem is, thus, concerned with minimizing total costs of providing products to customers. The proposed mechanism therefore aims to minimize total operation costs for the entire supply chain, including production, transportation, lost sales, inventory holding, and excess capacity components. Such supply chain is, therefore, more competitive by providing lower overall cost products to the end-customers. The supplies by received manufacturers are used to produce final products, without any wasted materials. Retailers are provided, at the start, with customer demand information for different product types for each period. Members should decide about on the quantities and sources of their orders.

Manufacturers and retailers are allowed to hold product inventory over time. In practice, distributors using the demand information, examine how to provide products from the manufacturers to the retailers to place orders. Therefore, distributors are considered as unpreventable intermediate nodes, and no excess inventory may remain with distributors as the end of planning periods. Contrary to distributors, holding inventory by retailers is commonplace.

\section{Flow networks}

The fundamental concept used in the proposed mechanism is the flow networks. A flow network is a directed graph in which each node can produce, consume or pass a flow. Each directed arc is a one-way conduit for the flow with a defined capacity. Nodes are conjunction points of flow paths and can only pass the flow (not store or consume it), except for two special types of nodes. A source node has outgoing $\operatorname{arc}(\mathrm{s})$ to produce the flow, and a sink node has only incoming arc(s) to consume the flow. Furthermore, a flow network may have several sources and sinks, rather than just one of each. Several studies, such as Ahuja, Magnanti and Orlin, (1993) and Goldberg, Tardos and Tarjan (1990), provide comprehensive surveys of algorithms for solving flow network problems.

Flow network $\mathrm{G}=(\mathrm{V}, \mathrm{E})$ is a directed graph in which each arc $(u, v) \in E$ has a nonnegative capacity, i.e. $c(u, v) \geq 0$. If $(\mathrm{u}, \mathrm{v}) \notin \mathrm{E}$, it is assumed that $\mathrm{c}(\mathrm{u}, \mathrm{v})=0$. Two nodes are distinguished in a typical flow network: source node $s$ and sink node $t$. Every arc lies on some path from the source to 
the sink. $f(u, v)$, which can be positive, zero or negative, is the flow from node $\mathrm{u}$ to node $\mathrm{v}$. A flow is a real-valued function $\mathrm{f}: \mathrm{V} \times \mathrm{V} \rightarrow \mathrm{R}$ that satisfies the following properties:

a) Capacity constraint: for all $u, v \in V$, require $\mathrm{f}(\mathrm{u}, \mathrm{v}) \leq \mathrm{c}(\mathrm{u}, \mathrm{v})$.

b) Skew symmetry: for all $\mathrm{u}, \mathrm{v} \in \mathrm{V}$, require $\mathrm{f}(\mathrm{u}, \mathrm{v})=-\mathrm{f}(\mathrm{v}, \mathrm{u})$.

c) Flow conservation: for all $\mathrm{u} \in \mathrm{V}-\{\mathrm{s}, \mathrm{t}\}$, require $\sum_{\mathrm{v} \in \mathrm{V}} \mathrm{f}(\mathrm{u}, \mathrm{v})=0$.

In case of multiple source or sink nodes, the source node or sink node should be replaced with a set of source nodes or a set of sink nodes in the aforementioned definition (Goldberg et al., 1990). Associated with each commodity is a demand, which is the amount of that commodity that should be shipped through the network. The multi-commodity flow problem covers shipping several different commodities from their respective sources to their sinks through a common network, so that total flow going through each edge does not exceed its capacity. The mechanism searches for a feasible multi-commodity flow solution, i.e. a way of shipping the commodities that satisfies the demands as well as the capacity constraints. This problem can be solved using either exact algorithms or approximation heauristics (Awerbuch \& Leighton, 1993; Garg \& Koenemann, 1998).

\section{Problem formulation}

Consider a directed graph $\mathrm{G}=(\mathrm{V}, \mathrm{E})$ where each node represents a member of the supply chain and each directed arc represents a potential relationship between two members. Every directed arc $(\mathrm{u}, \mathrm{v})$ shows the possibility of providing basic components, raw materials or finished products from member $\mathrm{u}$ to member $\mathrm{v}$. Arc capacities are given as capacities for supply, production, distribution and transportation from an organization to another for each period, depending on nature of a relationship. A cost factor is then assigned to each arc representing the costs of supply, production, distribution and transportation for each unit of a product or a component. These costs are assigned to the first member in a relationship (i.e. organization $u$ ). Notation used in the model is below:

$\mathrm{p}$ : index for number of different types of components/materials;

$\mathrm{k}$ : index for number of different of types of products;

$\mathrm{i}$ : index indicating type of product, where $\mathrm{i}=1,2, \ldots, \mathrm{k}$;

$\mathrm{j}$ : index indicating type of component (or raw material), where $\mathrm{j}=1,2, \ldots, \mathrm{p}$;

$\mathrm{t}$ : index indicating time period, where $\mathrm{t}=1,2, \ldots, \mathrm{T}$;

$\mathrm{a}_{\mathrm{ij}}$ : necessary quantity/amount of component/raw material type $\mathrm{j}$ necessary to produce every unit of product type i ;

$A_{i}=\left\{a_{i 1}, a_{i 2}, \ldots, a_{i p}\right\}:$ set of components/raw materials composing one unit of a product type $i$; (For example, if
$A_{4}=\{0,2,1\}$ then every unit of forth type of products contains two units of component type 2 and one unit of component type 3 . It is obvious that component type 1 is not needed to produce type of product).

Sset $=\left\{\mathrm{sp}_{\mathrm{s}}, \forall \mathrm{s}=1,2, \ldots, \mathrm{S}\right\}:$ set of suppliers;

Mset $=\left\{\operatorname{manu}_{\mathrm{m}}, \forall \mathrm{m}=1,2, \ldots, \mathbf{M}\right\}$ : set of manufacturers;

Dset $=\left\{\right.$ dist $\left._{\mathrm{d}}, \forall \mathrm{d}=1,2, \ldots, \mathrm{D}\right\}$ : set of distributors;

Rset $=\left\{\right.$ ret $\left._{\mathrm{r}}, \forall \mathrm{r}=1,2, \ldots, \mathrm{R}\right\}:$ set of retailers;

The original directed graph $\mathrm{G}$ representing the supply chain may be logically decomposed into two parts: Network(I) which includes manufacturers, distributors and retailers, and Network(II) which covers suppliers and manufacturers. In Network(I) products flow where manufacturers and retailers are considered as sources and sinks of flow, while in Network(II) components/raw materials flow where suppliers and manufacturers are to take these roles. However, a single integrated mathematical model, which involves both the Network(I) and Network(II), should be solved.

Network(I): a flow network with vertices consisting of Mset, Dset and Rset and arcs which connect these vertices;

Network(II): a flow network with vertices consisting of Sset and Mset and arcs which connect these vertices;

$\mathrm{V}_{1}$ : set of vertices of Network (I) $\left(\mathrm{V}_{1}=\right.$ Mset $U$ Dset $U$ Rset $)$; $\mathrm{V}_{2}$ : set of vertices of Network (II) $\left(\mathrm{V}_{2}=\right.$ Sset UMset $)$;

$\mathrm{V}$ : set of vertices of directed graph $\mathrm{G}$ (i.e. );

$\mathrm{d}_{\mathrm{irt}}$ : $\quad$ quantity of customer demand for product type from retailer $\mathrm{r}$ in period $\mathrm{t}(\mathrm{r}=1,2, \ldots, \mathrm{R})$;

$\mathrm{c}_{\mathrm{it}}(\mathrm{u}, \mathrm{v})$ : $\quad$ capacity of $\operatorname{arc}(\mathrm{u}, \mathrm{v})$ for flow of product $\mathrm{i}$ in period t (in Network(I));

$\mathrm{o}_{\mathrm{it}}(\mathrm{u}, \mathrm{v})$ : $\quad$ cost of flow of each unit of product $\mathrm{i}$ through $\operatorname{arc}(\mathrm{u}, \mathrm{v})$ in period t ((in Network $(I))$;

$f_{i t}(u, v)$ : value of flow of product type $i$ in $\operatorname{arc}(u, v)$ in period $\mathrm{t}$ (in Network $(I)$ );

$\mathrm{c}_{\mathrm{jt}}(\mathrm{u}, \mathrm{v})$ : capacity of $\operatorname{arc}(\mathrm{u}, \mathrm{v})$ for flow of component/material type $\mathrm{j}$ in period $\mathrm{t}$ (in Network(II));

$\mathrm{o}_{\mathrm{jt}}(\mathrm{u}, \mathrm{v})$ : cost of flow of component/material type $\mathrm{j}$ via $\operatorname{arc}(\mathrm{u}, \mathrm{v})$ in period $\mathrm{t}($ in Network $(I I))$;

$f_{j t}(u, v)$ : value of flow of component/material type $j$ via $\operatorname{arc}(\mathrm{u}, \mathrm{v})$ in period t (in Network $(I I))$;

$\mathrm{QP}_{\mathrm{imt}}$ : $\quad$ quantity of production of $\mathrm{i}$ th type of products in $\mathrm{m} t h$ manufacturer in period $\mathrm{t}$;

$\operatorname{Inv}(\mathrm{I})_{\mathrm{irt}}$ : inventory level corresponding to $\mathrm{r}$ th retailer and ith type of products at the beginning of the planning period $t$; 
$\operatorname{Inv}(\mathrm{II})_{\mathrm{irt}}$ : inventory level corresponding to $\mathrm{r}$ th retailer and ith type of products at the end of the planning period $\mathrm{t}$;

$\operatorname{Inv}(\mathrm{I})_{\mathrm{imt}}$ : inventory level corresponding to $\mathrm{m} t h$ manufacturer and ith type of products at the beginning of the planning period $t$;

$\operatorname{Inv}(\mathrm{II})_{\mathrm{imt}}$ : inventory level corresponding to $\mathrm{m} t h$ manufacturer and ith type of products at the end of the planning period $t$;

$\mathrm{H}_{\mathrm{irt}}$ : holding cost corresponding to $\mathrm{rth}$ retailer for every remained unit of ith type of products' inventory at the end of planning period $t$;

$\mathrm{H}_{\mathrm{imt}}$ : holding cost corresponding to $\mathrm{m} t h$ manufacturer for every remained unit of ith type of products' inventory at the end of planning period $\mathrm{t}$;

$\mathrm{LS}_{\text {irt }}$ : lost sale cost corresponding to $\mathrm{r}$ th retailer and every unit of $i$ th type of products in period $t$;

$\mathrm{ECC}_{\mathrm{it}}(\mathrm{u}, \mathrm{v})$ : excess capacity cost corresponding to arc $(\mathrm{u}, \mathrm{v})$ in period $\mathrm{t}\left(\mathrm{u}, \mathrm{v} \in \mathrm{V}_{1}\right)$;

$\mathrm{ECC}_{\mathrm{jt}}(\mathrm{u}, \mathrm{v})$ : excess capacity cost corresponding to arc $(\mathrm{u}, \mathrm{v})$ in period $\mathrm{t}\left(\mathrm{u}, \mathrm{v} \in \mathrm{V}_{2}\right)$;

$\mathrm{UC}_{\mathrm{imt}}$ : $\quad$ production cost for each unit of ith type of product by $\mathrm{m} t h$ manufacturer in period $\mathrm{t}$;

$\mathrm{PR}_{\mathrm{irt}}$ : order fulfilment priority assigned to $\mathrm{r} t h$ retailer and $\mathrm{i}$ th type of products in period $\mathrm{t}$ $\left(0<\mathrm{PR}_{\text {ir }} \leq 1\right)$;

$z$ : objective function representing the total cost incurred by the supply chain.

Parameters $\mathrm{c}_{\mathrm{it}}(\mathrm{u}, \mathrm{v}), \mathrm{c}_{\mathrm{jt}}(\mathrm{u}, \mathrm{v}), \mathrm{o}_{\mathrm{it}}(\mathrm{u}, \mathrm{v})$ and $\mathrm{o}_{\mathrm{jt}}(\mathrm{u}, \mathrm{v})$ are given as input data for the planning horizon. $c_{i t}(u, v)$ is interpreted as the maximum feasible capacity of organization $u$ (i.e. distributing and transporting) for providing product $\mathrm{i}$ and delivering it to organization $\mathrm{v}$ with cost $\quad \mathrm{o}_{\mathrm{it}}(\mathrm{u}, \mathrm{v})$. $\quad \mathrm{o}_{\mathrm{it}}(\mathrm{u}, \mathrm{v}) \quad$ is the distribution/transportation cost. $\mathrm{c}_{\mathrm{jt}}(\mathrm{u}, \mathrm{v})$ and $\mathrm{o}_{\mathrm{jt}}(\mathrm{u}, \mathrm{v})$ have similar interpretations replacing products with basic components/materials. $d_{i r t}$ is another input parameter to the model. $\mathrm{LS}_{\text {irt }}, \mathrm{H}_{\text {irt }}, \operatorname{Inv}(\mathrm{I})_{\mathrm{irt}}, \operatorname{Inv}(\mathrm{I})_{\mathrm{imt}}, \mathrm{ECC}_{\mathrm{it}}(\mathrm{u}, \mathrm{v})$, $\mathrm{ECC}_{\mathrm{jt}}(\mathrm{u}, \mathrm{v})$ and $\mathrm{UC}_{\mathrm{imt}}$ are also predefined parameters as inputs to the model, or they may be available from previous periods' data.

Parameter $\mathrm{PR}_{\text {irt }}$ can be initially assigned value one. If there is no feasible solution for the model, it might be reduced for some retailers with less cooperative background and solve the model again. Application of $\mathrm{PR}_{\text {irt }}$ as well as other parameters are clarified further in the next section. Finally, $\mathrm{f}_{\mathrm{it}}(\mathrm{u}, \mathrm{v}), \mathrm{f}_{\mathrm{jt}}(\mathrm{u}, \mathrm{v})$ and $\mathrm{QP}_{\mathrm{imt}}$ are decision variables. The proposed model for the whole supply chain is provided as follows:

$$
\begin{aligned}
& \min z= \\
& \left(\sum_{u, v \in V_{1}} \sum_{i=1}^{k} \sum_{t=1}^{T} o_{i t}(u, v) f_{i t}(u, v)\right)+\left(\sum_{u, v \in V_{2}} \sum_{j=1}^{p} \sum_{t=1}^{T} o_{j t}(u, v) f_{j t}(u, v)\right)+ \\
& \left(\sum _ { r = 1 } ^ { R } \sum _ { i = 1 } ^ { k } \sum _ { t = 1 } ^ { T } \left(\left(d_{i r t}-\operatorname{Inv}\left(I_{i r t}-\left(\sum_{u \in V_{1}} f_{i t}\left(u, r e t_{r}\right)\right) L S_{i r t}\right)\right)+\right.\right. \\
& \left(\left(\sum_{r=1}^{R} \sum_{i=1}^{k} \sum_{t=1}^{T}\left(\operatorname{Inv}(I)_{i r t} H_{i r t}\right)\right)+\left(\sum_{m=1}^{M} \sum_{i=1}^{k} \sum_{t=1}^{T}\left(\operatorname{Inv}(I)_{i m t} H_{i m t}\right)\right)+\right. \\
& \left(\sum_{u, v \in V_{1}} \sum_{t=1}^{T}\left(\sum_{i=1}^{k}\left(c_{i t}(u, v)-f_{i t}(u, v)\right) E C C_{i t}(u, v)\right)\right)+ \\
& \left(\sum_{u, v \in V_{2}} \sum_{t=1}^{T}\left(\sum_{j=1}^{p}\left(c_{j t}(u, v)-f_{j t}(u, v)\right) E C C_{j t}(u, v)\right)\right)+ \\
& \left(\sum_{t=1}^{T} \sum_{m=1}^{M} \sum_{i=1}^{k} Q_{i=1} P_{i m t} U C_{i m t}\right)
\end{aligned}
$$

subject to

$$
\begin{aligned}
& \mathrm{f}_{\mathrm{it}}(\mathrm{u}, \mathrm{v}) \leq \mathrm{c}_{\mathrm{it}}(\mathrm{u}, \mathrm{v}) \quad \forall \mathrm{i}=1,2, \ldots, \mathrm{k} \text { and } \\
& \forall \mathrm{u}, \mathrm{v} \in \mathrm{V}_{1} \text { and } \forall \mathrm{t}=1,2, \ldots, \mathrm{T} ; \quad \text { (2) } \\
& \mathrm{f}_{\mathrm{it}}(\mathrm{u}, \mathrm{v})=-\mathrm{f}_{\mathrm{it}}(\mathrm{v}, \mathrm{u}) \quad \forall \mathrm{i}=1,2, \ldots, \mathrm{k} \text { and } \\
& \forall \mathrm{u}, \mathrm{v} \in \mathrm{V}_{1} \text { and } \quad \forall \mathrm{t}=1,2, \ldots, \mathrm{T} ; \\
& \sum_{\mathrm{v} \in \mathrm{V}_{1}} \mathrm{f}_{\mathrm{it}}(\mathrm{u}, \mathrm{v})=0 \quad \forall \mathrm{i}=1,2, \ldots, \mathrm{k} \text { and } \\
& \forall \mathrm{u} \in \text { Dset and } \forall \mathrm{t}=1,2, \ldots, \mathrm{T} ;
\end{aligned}
$$

$\sum_{\mathrm{u} \in \mathrm{V}_{\mathrm{i}}} \mathrm{f}_{\mathrm{it}}\left(\mathrm{u}, \mathrm{ret}_{\mathrm{r}}\right) \geq\left(\mathrm{d}_{\text {irt }}-\operatorname{Inv}(\mathrm{I})_{\text {irt }}\right) \mathrm{PR}_{\text {irt }}$

$\forall \mathrm{i}=1,2, \ldots, \mathrm{k}$ and $\forall \mathrm{r}=1,2, \ldots, \mathrm{R}$ and

$\forall \mathrm{t}=1,2, \ldots, \mathrm{T}$;

$\mathrm{f}_{\mathrm{jt}}(\mathrm{u}, \mathrm{v}) \leq \mathrm{c}_{\mathrm{jt}}(\mathrm{u}, \mathrm{v}) \quad \forall \mathrm{j}=1,2, \ldots, \mathrm{p}$ and

$\forall \mathrm{u}, \mathrm{v} \in \mathrm{V}_{2}$ and $\forall \mathrm{t}=1,2, \ldots, \mathrm{T}$;

$$
\begin{aligned}
& \sum_{\mathrm{u} \in \mathrm{V}_{2}} \mathrm{f}_{\mathrm{jt}}\left(\mathrm{u}, \mathrm{manu}_{\mathrm{m}}\right) \geq \sum_{\mathrm{i}=1}^{\mathrm{k}}\left(\mathrm{a}_{\mathrm{ij}} \sum_{\mathrm{v} \in \mathrm{V}_{1}} \mathrm{f}_{\mathrm{it}}\left(\mathrm{manu}_{\mathrm{m}}, \mathrm{v}\right)\right) \\
& \forall \mathrm{j}=1,2, \ldots, \mathrm{p} \text { and; } \forall \mathrm{m}=1,2, \ldots, \mathrm{M} \text { and } \\
& \forall \mathrm{t}=1,2, \ldots, \mathrm{T} ;
\end{aligned}
$$

$$
\begin{aligned}
& \mathrm{QP}_{\mathrm{imt}}+\operatorname{Inv}(\mathrm{I})_{\mathrm{imt}} \geq \sum_{\mathrm{v} \in \mathrm{V}_{1}} \mathrm{f}_{\mathrm{it}}\left(\mathrm{manu}_{\mathrm{m}}, \mathrm{v}\right) \\
& \forall \mathrm{j}=1,2, \ldots, \mathrm{p} \text { and; } \forall \mathrm{m}=1,2, \ldots, \mathrm{M} \text { and } \\
& \forall \mathrm{t}=1,2, \ldots, \mathrm{T} ;
\end{aligned}
$$

$\left(d_{\text {irt }}-\operatorname{Inv}(\mathrm{I})_{\text {irt }}-\sum_{d=1}^{D} f_{i t}\left(\operatorname{dist}_{d}, \operatorname{ret}_{r}\right)\right) \geq 0$

$\forall \mathrm{h} \mathrm{i}=1,2, \ldots, \mathrm{k}$ and $\forall \mathrm{r}=1,2, \ldots, \mathrm{R}$ and

$\forall \mathrm{t}=1,2, \ldots, \mathrm{T}$; 


$$
\begin{aligned}
& \mathrm{f}_{\mathrm{jt}}\left(\mathrm{sp}_{\mathrm{s}}, \mathrm{manu}_{\mathrm{m}}\right) \geq 0 \quad \forall \mathrm{s}=1,2, \ldots, \mathrm{S} \text { and } \\
& \forall \mathrm{m}=1,2, \ldots, \mathrm{M} \text { and } \\
& \forall \mathrm{j}=1,2, \ldots, \mathrm{p} \text { and } \forall \mathrm{t}=1,2, \ldots, \mathrm{T} \\
& \mathrm{f}_{\mathrm{it}}\left(\mathrm{manu}_{\mathrm{m}}, \mathrm{dist}_{\mathrm{d}}\right) \geq 0 \quad \forall \mathrm{m}=1,2, \ldots, \mathrm{M} \text { and } \\
& \forall \mathrm{d}=1,2, \ldots, \mathrm{D} \text { and } \\
& \forall \mathrm{i}=1,2, . \mathrm{k} \text { and } \forall \mathrm{t}=1,2, \ldots, \mathrm{T} ; \\
& \mathrm{f}_{\mathrm{it}}\left(\mathrm{dist}_{\mathrm{d}}, \mathrm{ret}_{\mathrm{r}}\right) \geq 0 \\
& \forall \mathrm{d}=1,2, \ldots, \mathrm{D} \text { and } \\
& \forall \mathrm{r}=1,2, \ldots, \mathrm{R} \text { and } \\
& \forall \mathrm{i}=1,2, \mathrm{k} \text { and } \forall \mathrm{t}=1,2, \ldots, \mathrm{T} ; \\
& \mathrm{QP}_{\mathrm{imt}} \geq 0 \quad \mathrm{~m}=1,2, \ldots, \mathrm{M} \quad \text { and } \\
& \forall \mathrm{i}=1,2, . \mathrm{k} \text { and } \forall \mathrm{t}=1,2, \ldots, \mathrm{T} ;
\end{aligned}
$$

The proposed model is described by expressions (1-13). Expression (1) shows the objective function, indicating total operational costs of the supply chain. It consists of eight terms logically separated by parentheses. The first and second terms indicate flow costs (i.e. purchasing and transportation costs) in Network(I) and Network(II), respectively. The third term shows the cost of lost sales. The fourth and the fifth parentheses represent holding cost of remaining inventory from the previous period. Costs incurred in the supply chain from the excess capacity in Network(I) and Network(II) are shown by the two subsequent terms. Finally, the eighth term stands for the production costs.

There are twelve constraint sets denoted by numbers (2) to (13) in the model. First three constraint sets $(2,3,4)$ are equivalent to capacity constraint, skew symmetry and flow conservation properties of flow networks (for Network(I)), respectively. Constraint set (5) guarantees satisfying demand for the retailers. Constraints (6) are equivalent to capacity constraint of flow networks (for Network(II)). Constraints (7) guarantee satisfying demand from the manufacturers for basic components to produce sufficient products. Constraints (8) assure sufficient production by the manufacturers. Constraints (9) both assure non-negativity of lost sales and not having excess inventory at retailers (note that similar constraints for manufacturers are implicitly satisfied according to model). Finally, constraints (10), (11), (12) and (13) are non-negativity constraints on the values of out flows and quantities of product.

Note that if supply chain members choose order quantities only according to the timed solution of the model, they will not have any excess inventory. However, they may opt for holding inventory because of their own forecast of future demands or keeping safety stock (i.e. $\operatorname{Inv}(\mathrm{II})_{\mathrm{ir}} \geq 0$ or $\left.\operatorname{Inv}(\mathrm{II})_{\mathrm{im}} \geq 0\right)$. Therefore, $\operatorname{Inv}(\mathrm{I})_{\mathrm{irt}}$ and $\operatorname{Inv}(\mathrm{I})_{\mathrm{imt}}$ are not necessarily zero at the beginning of the upcoming planning period. The model above is a linear programming model, and existing polynomial-time algorithms such as Karmarkar's algorithm (Karmarkar, 1984) can be used to solve it efficiently. Upon solving the model and informing the supply chain members of their respective flow values, they are able to place orders accordingly, for an optimal situation for the whole supply chain.

\section{The optimizer mechanism}

To coordinate the cooperative members of the supply chain in practice, a central software entity named Cooperative Supply Optimizer System (CSOS) plays a central role whose architecture is described later in this section. The suppliers and manufacturers are asked to provide $A_{i}$ sets information to the CSOS. Whenever $\mathrm{A}_{\mathrm{i}}$ changes, they can inform the CSOS immediately. At the beginning of a planning period, for example at beginning of each month, the retailers also provide demand forecast information to the CSOS. Every supplier, manufacturer and distributor in supply chain provides the CSOS with names of connected organizations in its next stage along with associated capacity and cost parameters. In other words, a retailer ret $_{r}$ sends $d_{i r}$ and every non-retailer member of supply chain such as $u$ specifies $\operatorname{arcs}(\mathrm{u}, \mathrm{v})$ and values for $\mathrm{c}_{\mathrm{it}}(\mathrm{u}, \mathrm{v})$ and $\mathrm{o}_{\mathrm{it}}(\mathrm{u}, \mathrm{v})$ to the CSOS. Formally, Info(u) denoting information given to the CSOS by member of the supply chain is defined for different members as follows:

$$
\text { Info }\left(\mathrm{sp}_{\mathrm{s}}\right)=\left\{\begin{array}{l}
\left(\mathrm{c}_{\mathrm{j}}\left(\mathrm{sp}_{\mathrm{s}}, \mathrm{v}\right), \mathrm{o}_{\mathrm{j}}\left(\mathrm{sp}_{\mathrm{s}}, \mathrm{v}\right), \mathrm{ECC}_{\mathrm{j}}\left(\mathrm{sp}_{\mathrm{s}}, \mathrm{v}\right):\right. \\
\mathrm{j}=1,2, \ldots, \mathrm{p} \text { and } \mathrm{t}=1,2, \ldots, \mathrm{T} \text { and } \\
\left(\mathrm{sp}_{\mathrm{s}}, \mathrm{v}\right) \in \mathrm{E}
\end{array}\right\}
$$

Info $\left(\mathrm{manu}_{\mathrm{m}}\right)=\left\{\begin{array}{l}\left(\mathrm{c}_{\mathrm{i}}\left(\mathrm{manu}_{\mathrm{m}}, \mathrm{v}\right), \mathrm{o}_{\mathrm{i}}\left(\mathrm{manu}_{\mathrm{m}}, \mathrm{v}\right),\right. \\ \mathrm{ECC}_{\mathrm{i}}\left(\mathrm{manu}_{\mathrm{m}}, \mathrm{v}\right), \\ \left.\operatorname{Inv}(\mathrm{I})_{\mathrm{im}}, \mathrm{H}_{\mathrm{im}}, \mathrm{UC} \mathrm{C}_{\mathrm{im}}\right): \mathrm{i}=1,2, \ldots, \mathrm{k} \\ \text { and } \mathrm{t}=1,2, \ldots, \mathrm{T} \text { and }\left(\mathrm{manu}_{\mathrm{m}}, \mathrm{v}\right) \in \mathrm{E}\end{array}\right\}$

Info $\left(\right.$ dist $\left._{\mathrm{d}}\right)=\left\{\begin{array}{l}\left(\mathrm{c}_{\mathrm{i}}\left(\text { dist }_{\mathrm{d}}, \mathrm{v}\right), \mathrm{o}_{\mathrm{i}}\left(\text { dist }_{\mathrm{d}}, \mathrm{v}\right), \mathrm{ECC}_{\mathrm{i}}\left(\text { dist }_{\mathrm{d}}, \mathrm{v}\right)\right) \\ : \mathrm{i}=1,2, . . \mathrm{k} \text { and } \mathrm{t}=1,2, \ldots, \mathrm{T} \text { and } \\ \left(\text { dist }_{\mathrm{d}}, \mathrm{v}\right) \in \mathrm{E}\end{array}\right\}$

Info $\left(\operatorname{ret}_{\mathrm{r}}\right)=\left\{\begin{array}{l}\left(\mathrm{d}_{\mathrm{ir}}, \operatorname{Inv}(\mathrm{I})_{\mathrm{ir}}, \mathrm{H}_{\mathrm{ir}}, \mathrm{LS}_{\mathrm{ir}}\right): \mathrm{i}=1,2, \ldots, \mathrm{k} \text { and } \\ \mathrm{t}=1,2, \ldots, \mathrm{T}\end{array}\right\}$

The most cooperative case is providing the CSOS with information according to the above four set. As a minimum, only $\mathrm{c}(\mathrm{u}, \mathrm{v}), \mathrm{o}(\mathrm{u}, \mathrm{v})$ and $\mathrm{d}_{\mathrm{irt}}$ are sufficient to form the optimization model (Fayazbakhsh, 2007). In the latter case, unknown parameters may be forecast based on previous periods' information. In the worst case, in which no information is available, when these parameters are not given by some members, corresponding terms may be omitted from objective functions and constraints. This results in a less optimal but still a quite helpful model.

Priority parameter $\mathrm{PR}_{\mathrm{ir}}$ which is set by the CSOS, reflects cooperative records of a member (the greater value means a more cooperative behaviour). Cooperation is the degree to which a supply chain member abides by the order quantities declared by the CSOS. This parameter might take initial value of one. If there is not any feasible solution from the 
model due to limited flow capacity, the CSOS could reduce priority parameters for members with less cooperative records. As a result, tendency to become selfish, and act in a locally-optimum fashion, will be deterred over time.

With gathered information, the CSOS is then able to construct and solve the optimization model and send the flow values to the supply chain members. These orders are placed to assure the entire supply chain operation works with minimum feasible costs and satisfies customer demands. Decision information provided by the CSOS for manufacturer $\operatorname{manu}_{\mathrm{m}}$, distributor dist $_{\mathrm{d}}$ and ret $_{\mathrm{r}}$ retailer are denoted by expressions (18), (19) and (20):

Decision - Info $\left(\operatorname{manu}_{\mathrm{m}}, \mathrm{u}, \mathrm{j}\right)=\left\{\begin{array}{l}\left(\mathrm{f}_{\mathrm{jt}}\left(\mathrm{u}, \mathrm{manu}_{\mathrm{m}}\right), \mathrm{QP} \mathrm{imt}_{\mathrm{imt}}\right): \\ \left(\mathrm{u}, \operatorname{manu}_{\mathrm{m}}\right) \in \mathrm{E} ; \\ \mathrm{j}=1,2, \ldots, \mathrm{p} \text { and } \\ \mathrm{t}=1,2, \ldots, \mathrm{T} \text { and } \\ \mathrm{m}=1,2, \ldots, \mathrm{M}\end{array}\right\}$

Decision - Info $\left(\right.$ dist $\left._{d}, u, i\right)=\left\{\begin{array}{l}f_{i t}\left(u, \text { dist }_{d}\right):\left(u, \text { dist }_{d}\right) \in E \\ i=1,2, \ldots, k \text { and } \\ t=1,2, \ldots, T \text { and } \\ d=1,2, \ldots, D\end{array}\right\}$

Decision-Info $\left(\right.$ ret $\left._{r}, u, i\right)=\left\{\begin{array}{l}f_{i t}\left(u, r_{r} t_{r}\right):\left(u, r_{r}\right) \in E \\ i=1,2, \ldots, k \text { and } \\ t=1,2, \ldots, T \text { and } \\ r=1,2, \ldots, R\end{array}\right\}$

\section{Evaluation}

A corresponding simulation program is developed and run. Its results show how the proposed solution performs and helps in different situations. The locally optimum behaviors by individual members are considered as a benchmark comparison, to determine usefulness and the performance of the proposed mechanism (Appendix A). Consider performance ratio (I) as an indicator for this purpose:

Performance Ratio $(\mathrm{I})=\frac{\text { Total Cost without CSO }}{\text { Total Cost with CSO }}$

It is also determined how the performance ratio is dependant on the variety of flows in the supply chain. $\mathrm{k}+\mathrm{p}$ is a metric to represent variety of flows in the supply chain. A sample simulated supply chain contains 70 suppliers, 10 manufacturers, 20 distributors and 50 retailers. Values for $\mathrm{k}$ and $\mathrm{p}$ are set randomly such that $\mathrm{k}<\mathrm{p}$ and their summation equals the intended value. A planning period of one year, or twelve monthly periods, is considered during the simulation. Figure 1 depicts simulation results from
ILOG CPLEX 11.0 standard mathematical programming solver.

The average value for performance ratio is 1,354 or $26,14 \%$ reduction in total costs. Its performance ratio is always higher than 1,332, and it increases as the variety in supply chain increases. Therefore, the proposed model performs better and is more valuable in cases of high variety supply chains. In order to determine effectiveness of the mechanism in different sizes of the supply chain, the problem is simulated considering a supply chain providing 20 different products from 150 various components. Network size can be expressed as the total number of supply chain members.

Network Size $=S+M+D+R$

During the simulation random values for number of members are set such that $\mathrm{D} \geq \mathrm{M}, \quad \mathrm{R} \geq \mathrm{D}$ and $\mathrm{S} \geq \mathrm{M}$. Figure 2 illustrates how performance ratio varies with network size.

Considering the average value for performance ratio is 1.358 , it can be concluded that network size does not affect the performance ratio. Next is to investigate how the ratio (percentage) of misbehaving members, those that do not behave in a locally optimum style, affects the performance ratio. Consider a supply chain with 70 suppliers, 10 manufacturers, 20 distributors and 50 retailers in which 20 different products from 150 various components flow.

Note that the number of misbehaving members in each stage of the supply chain is appropriate to relative number of the stage's members comparing with the whole number of supply chain members. Figure 3 depicts the effect of the percentage of misbehaving members, i.e. $\mathrm{P}_{-}$Misbehaving, on the performance ratio.

According to simulation results, performance ratio deteriorates when the percentage of misbehaving members increase. With $\mathrm{P}_{-}$Misbehaving $=10 \%$ the performance ratio is equal to 1,23 . When $\mathrm{P}_{-}$Misbehaving $=30 \%$ the performance ratio falls to 1,07 . A stable performance ratio about 1.03 is observed when $\mathrm{P}_{-}$Misbehaving $\geq 40 \%$. Thus, a higher percentage of misbehaving members leads to lower effectiveness of the proposed solution.

\section{Just-in-time supply chain}

The concept of Just-in-time purchasing, originally publicized by success of Toyota in Japan and was later accepted by corporations globally, requires that the requirements are ordered and delivered each period to match the exact requirements of materials and products (Sepehri, 1986). Under such system, only current requirements are considered and no inventory is to be held. 


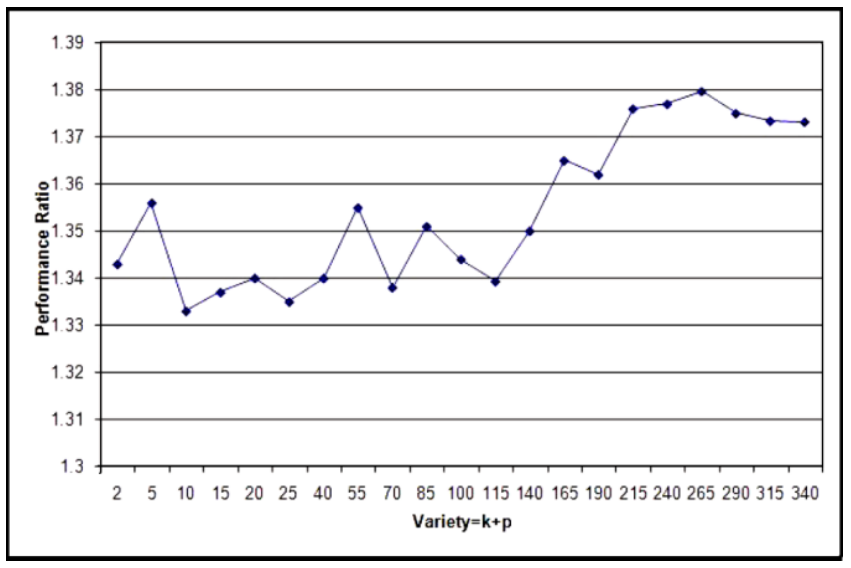

Figure 1: Performance ratio as a function of variety

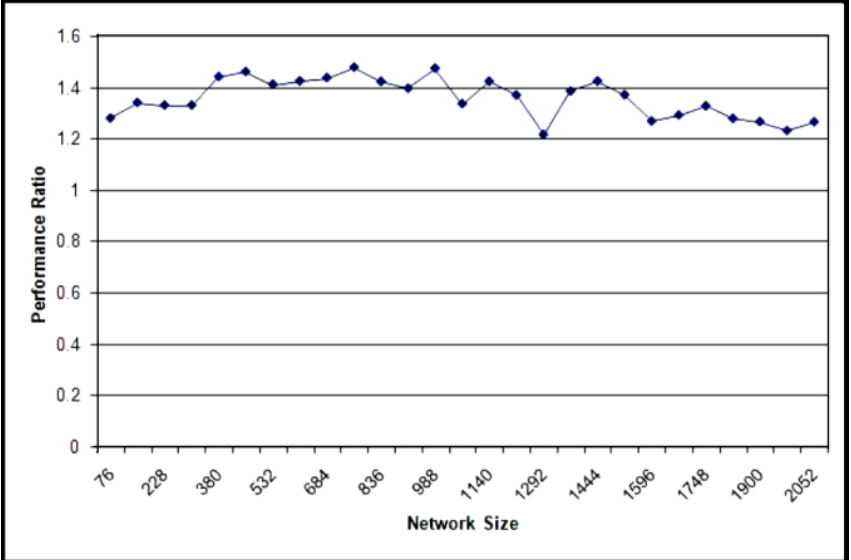

Figure 2: Performance ratio as a function of network size

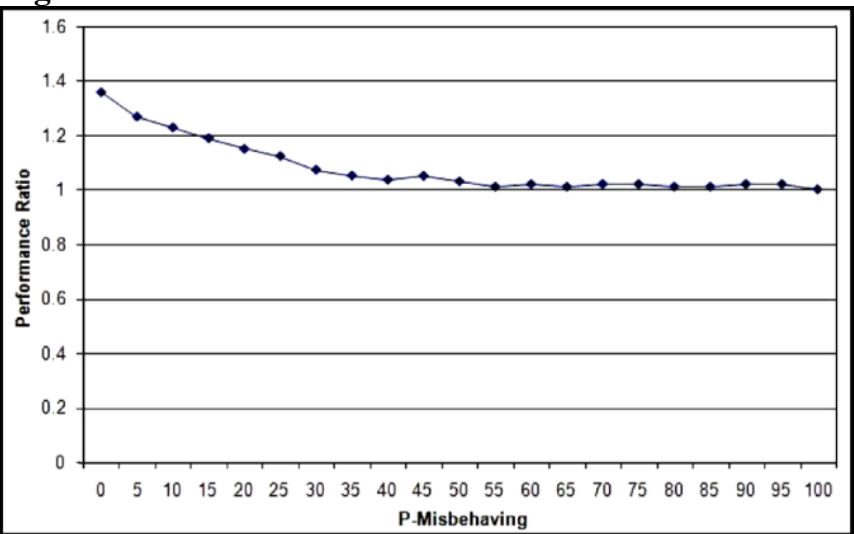

Figure 3: Performance ratio as a function of percentage misbehaving members

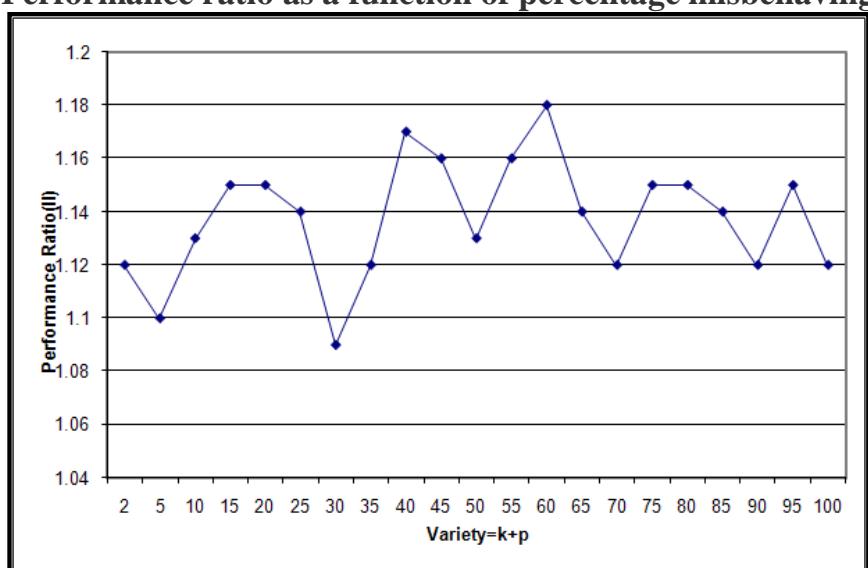

Figure 4: Impact of number of planning periods 
It is also insightful to evaluate the significance of the number of planning periods used in finding the solution for supply chain. Obviously, a globally optimized multi-period total costs is better than the sum of sub-optimum singleperiod solutions. For an example here, a small sample with three periods is used. Hence, performance ratio (II) is considered based on the following definition:

Performance Ratio $($ II $)=\frac{\text { Total Cost with CSO when } \mathrm{T}=1}{\text { Total Cost with CSO } \mathrm{T}=3}$

In this example, the same parameters and supply chain setup are used as above in the simulation. As expected and also depicted by the graph in Figure 4, a three-month planning horizon is more cost effective in comparison to a singlemonth. It varies again as the variety in supply chain increases. In this example, the average value for performance ratio is 1,138 or $12,13 \%$ reduction in total costs.

As the number of periods in the planning horizon increases, the performance ratio also increases. However, the rate of increase diminishes rapidly. For the above example, if the number of periods increases from 3 to 6 , the average performance ratio in the simulation increases from 1,138 to 1,174. Therefore, periods beyond the first few are insignificant, even though some inventory is to be held.
Just-in-time (JIT) approach implies lack of necessity to hold inventory. However, it requires accurate planning and supply mechanisms (Hutchins, 1999). In the proposed problem, supply chain members may hold inventory, per available information about future, if costs of the supply chain may indicate buying and holding some items is more cost effective than buying the items in a future period when they are needed. However, a higher holding cost cancels out the preference to hold inventory.

To determine the impact of the holding costs, the supply chain is simulated at different levels of holding costs, while all the other parameters of the model are fixed. To validate the JIT concept, the holding cost parameters of the supply chain are increased so that no inventory is held. Very quickly, supply chain members only purchase components/products that they need in the current period.

It may be concluded from the simulation results illustrated in Figure 5 that increasing the holding costs results in a lower performance ratio (II). It will in fact occur when the cost of holding inventory exceeds the difference of purchasing another cooperative member in that same stage. Due to impact of higher inventory costs, supply chain members opt to purchase their current needs and hold fewer inventories. In practice, the point of no inventory (JIT) is reached quickly, as the multiple components of holding costs commonly add up. This is another indication that lengthy forecasts are not needed in cooperative supply chains, and Just-in-time system would prevail.

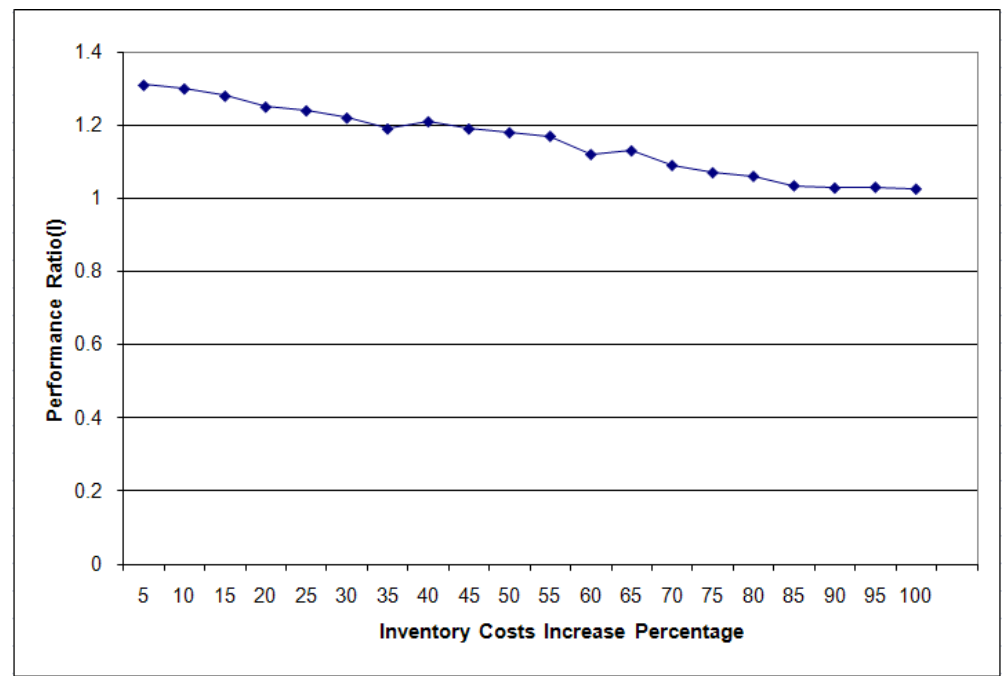

Figure 5: Performance ratio II as a function of increase in the inventory costs

\section{The bullwhip effect}

A phenomenon that is now well known as the bullwhip effect suggests that the variability of orders increases as they move up the supply chain from retailers to wholesalers to manufacturers to suppliers (Lee, Padmanabhan \& Whang, 1997a, b; Kahn, 1987). The first academic description of the bullwhip phenomenon is ascribed to Forrester (1961), who explained it as a lack of information looping between the members of the supply chain and by the existing non-linear interactions, which are difficult to deal with using managerial intuition.
In a supply chain, although consumer sales do not seem to vary much, there is pronounced variability in the retailer's orders to the wholesaler. Furthermore, the wholesaler's order quantities to the manufacturer as well as the manufacturer's orders to the supplier vary even more in time (Metters, 1997). This effect creates a problem for coordination by an amplification of demand variability in the supply chain, so that the suppliers receive orders more variable and unpredictable than the retailers (Anderson, Fine $\&$ Parker, 2000). The semiconductor equipment industry is, 
for example, more volatile than the personal computer industry (Terwiesch et al., 2005).

The bullwhip effect may have a number of negative effects in real supply chains, causing significant inefficiencies. The bullwhip effect typically leads to excessive inventory investments throughout the supply chain as the parties involved need to protect themselves against demand variations (Cachon, Randall \& Schmidt, 2005). This problem leads to unnecessary inventory and decreased customer service levels due to backorders, which includes inventory shortages and lost sales (Lee et al., 1997 ). Вy eliminating or controlling the bullwhip effect, it is possible to increase supply chain's profitability (Strozzi \& Zaldivar, 2008). Reducing the bullwhip effect is based on considering the supply chain as a dynamic system and the application of control techniques are recently summarized by Sarimveis, Patrinos and Tarantilis (2008).

It was shown earlier that wide-deviations in competitive behaviour actually disappears in cooperative supply chains. In evaluating further deviations and problems for the members from the optimum solution, another criterion for evaluation of proposed solution is the effect of bullwhip phenomenon. Since the integrated solution assumes cooperative information sharing among supply chain members, it may be argued or verified by the simulation that there is no bullwhip effect in the supply chain.

\section{Summary and conclusion}

Members in a traditional supply chain competed selfishly to minimize their own local costs, even assuming that the customer demand is given and the price is fixed amongst all the suppliers. The trend has changed towards cooperative supply chains and corporate-managed supply networks, in which the members collaborate to minimize the overall cost of the entire supply chain, in a general case of multimember, multi-stage, multi-product and multi-period. This paper models and solves the planning decisions in the cooperative supply chains. It also compares the solution with the traditional competitive ones, to show that the members gain a lower cost average and a lower cost variance over time. Given a multi-period set of customer demand, inventory is allowed to be held at manufacturing or retailers to lower the overall multi-period cost.

A flow network is developed using an integrated supply chain framework, by developing and solving a set of linear programming models. Considering operation capacities and costs for all members in the supply chain, each type of product is produced from a set of basic components or raw materials and sent to the distributors to satisfy the customer demands. The solution enables members to reach decisions with minimum cost for the entire supply chain. From simulation results of aforementioned formulation, the proposed solution responds efficiently in different situations. It is also shown that only a small number of periods are practically effective in the multi-period solution. The problem becomes a single period (JIT), if inventory holding costs increase. The bullwhip effect of competitive supply chains, it is argued and exhibited, disappears as members act in integrated competitive fashion.
The paper also proposes a software-based coordination mechanism for a cooperative multi-stage, multi-member, multi-product supply chain. A central entity, Cooperative Supply Optimizer System (CSOS), receives information about relations, capacities, costs and operational parameters from members of at the beginning of the planning period. It a corresponding linear programming model and sends optimal order quantities to the members. CSOS may get the information about the behaviour of the members (directly from themselves or indirectly inferred from received information on the whole supply chain). It may punish selfish members (i.e. members that tend to act based on their locally-optimum preference rather than the solution provided by CSOS), with reduction of their order fulfilment priority factor in the upcoming periods. CSOS may be implemented with practical IT-based architectures in the real world.

This paper extends the previous limited scope studies, by the authors, to multiple-period, multiple-stage and multipleproduct cooperative supply chains. Obviously, most realworld scenarios involve more intricate and complicated characteristics such as stochastic nature of demand or application of different inventory management systems. The proposed preliminary coordination mechanism may be further broadened and studied with potential for more complex situations.

\section{References}

Ahuja, R. K., Magnanti, T. L. \& Orlin, J. B. 1993. Network flows: Theory, algorithms, and applications. United States: Prentice Hall.

Almansoori, A. \& Shah, N. 2009. 'Design and operation of a future hydrogen supply chain: Multi-period model', International Journal of Hydrogen Energy, 34(19): 78837897.

Amiri, A. 2006. 'Designing a distribution network in a supply chain system: Formulation and efficient solution procedure', European Journal of Operational Research, 171(2): 567-576.

Anderson, E., Fine, C. \& Parker, G. 2000. 'Upstream volatility in the supply chain: The machine tool industry as a case study', Production and Operations Management Journal, 9: 239-261.

Awerbuch, B. \& Leighton, T. 1993. 'A simple local-control approximation algorithm for multi-commodity flow'. In The Proceedings of 34th Annual Symposium on Foundations of Computer Science. Palo Alto, CA: IEEE-Wiley.

Baraldi, E. 2008. 'Strategy in industrial networks: Experiences from IKEA', California Management Review, 50(4): 118-120.

Barbarsoglu, G. \& Ozgur, D. 1999. 'Hierarchical design of an integrated production and 2-echelon distribution system', European Journal of Operational Research, 118:464-484. 
Boudiaa, M. \& Prins, C. 2007. 'A memetic algorithm with dynamic population management for an integrated production-distribution problem', European Journal of Operational Research, 195(3):703-715.

Bourland, K. E., Powell, S. G. \& Pyke, D. F. 1996. 'Exploiting timely demand information to reduce inventories', European Journal of Operational Research, 92(2):239-253.

Brusco, S. 1996. 'The games of districts'. Paper presented at the ESF-EMOT Conference Inter-firm networks: Outcomes and policy implications, Modena, Italy.

Byrne, M. D. \& Bakir, M. A. 1999. 'Production planning using a hybrid simulation - analytical approach', International Journal of Production Economics, 59: 305311.

Cachon., G. P. 2003. 'Supply chain coordination with contracts'. In Graves, S. \& De Kok, T. (eds.). Handbooks in operations research and management science - supply chain management: Design, coordination and operation. Amsterdam, Netherlands: Elsevier Publishing Company.

Cachon, G. P. \& Fisher, M. 2000. 'Supply chain inventory management and the value of shared information', Management Science, 46(8):1032-1048.

Cachon, G. P. \& Lariviere, M. 2005. 'Supply chain coordination with revenue-sharing contracts: Strengths and limitations', Management Science, 51(1): 30-44.

Cachon, G. P. \& Zipkin, P. H. 1999. 'Competitive and cooperative inventory policies in a two-stage supply chain', Management Science, 45(7): 936-953.

Cachon, G.P., Randall, T. \& Schmidt, G.M. 2005. 'In search of the bullwhip effect', Manufacturing and Service Operations Management 9(4): 457-479.

Campbell A., Devine, M. \& Young, D. 1993. A sense of mission. Readings, Mass: Addison-Wesley.

Chen, Z. 2004. 'Integrated production and distribution operations: Taxonomy, models, and review'. In SimchiLevi, D. Wu, S.D. \& Shen, Z-J. (Eds.). Handbook of quantitative supply chain Analysis: Modeling in the EBusiness Era. Kluwer by Academic Publishers.

Chen, Y., Peng, Y., Finin, T., Labrou, Y. \& Cost, S. 1999. 'A negotiation-based multi-agent system for supply chain management'. In Proceedings of Workshop on Agent based Decision-Support for Managing the Internet-Enabled Supply-Chain, at Third Conference on Autonomous Agents (Agents-99), Seattle, WA.

Chopra, S. 2003. 'Designing the delivery network for a supply chain', Transportation Research, Part E, 39(2): 123140.
Chopra, S. \& Meindl, P. 2003. Supply chain management: Strategy, planning and operations. United States: PrenticeHall.

Christopher, M. 1998. Logistics and supply chain management. $2^{\text {nd }}$ Edition. London: Pitman.

Cohen, M. A. \& Lee, H. L. 1988. 'Strategic analysis of integrated production-distribution systems: Models and methods', Operations Research, 36: 216-228.

Collis, D. \& Montgomery, C. 2004. Corporate strategy. New York, NY, USA: John Wiley.

Contractor, F.J. \& Lorange, P. 1988. Cooperative strategies in international business. Boston: Lexington Books.

Corrêa, H. L. \& De Miranda, N. G. M. 1998. 'Supply network management in the Brazilian automotive industry', Integrated Manufacturing Systems, 9(5): 261-271.

Cusumano, M. \& Takeishi, A. 1991. 'Supplier relations and management: A survey of Japanese, Japanese-transplant, and U.S. auto plants', Strategic Management Journal, 12(8):563-588.

Daskin, M. S. 1995. Network and discrete location. New York: John Wiley and Sons.

De Wit, B. \& Meyer, R. 2004. Strategy, process, content, context - an international perspective. $3^{\text {rd }}$ Edition. London: Thomson Publishing.

Dhaenens-Flipo, C. \& Finke, G. 2001. 'An integrated model for an industrial production-distribution problem', IIE Transactions, 33: 705-715.

Ding, D. \& Chen, J. 2008. 'Coordinating a three level supply chain with flexible return policy', Omega, 36(5) 865876.

Dogan, K. \& Goetschalckx, M. 1999. 'A primal decomposition method for the integrated design of multiperiod production-distribution systems', IIE Transactions, 31:1027-1036.

Dudek, G. \& Stadtler, H. 2005. 'Negotiation-based collaborative planning between supply chain partners', European Journal of Operational Research, 163(3): 668687.

Dyer, J. H. 1996, 'Specialized supplier networks as a source of competitive advantage: Evidence from the auto industry', Strategic Management Journal, 17(4): 271-292.

Dyer, J. H., Cho, D. S. \& Chu, W. 1998 'Strategic supplier segmentation', California Management Review, 40(2):5777 .

Eng, T. Y. 2004. 'The role of e-marketplaces in supply chain management', Industrial Marketing Management, 33(2): 97-105. 
Fayazbakhsh, K. 2007. 'A coordination mechanism for a multiple-member supply chain'. M.Sc. Thesis, Department of Computer Engineering and IT, Amirkabir University of Technology, Iran.

Fayazbakhsh, K. \& Sepehri, M. 2010. 'Corporate supply optimizer with flow networks', Scientica Iranica Journal, 1. 18: $318-329$.

Fazel Zarandi, M.H., Moattar Hosein, S.M., Bastani, S. \& Mohebi, A. 2008. 'A fuzzy intelligent information agent architecture for supply chains', Scientia Iranica, 15(5): 623636.

Fink, A. 2004. 'Supply chain coordination by means of automated negotiations'. In Proceedings of 37th Hawaii International Conference on System Sciences. , Hamburg, Germany.

Forrester, J.W. 1961. Industrial dynamics. Cambridge, Massachusetts: MIT Press.

Fox, M.S., Barbuceanu, M. \& Teigen, R. 2000. 'Agentoriented supply-chain management', International Journal of Flexible Manufacturing Systems, 12(2-3):165-188.

Fox, M.S., Chionglo, J.F. \& Barbuceanu, M. 1993. 'The integrated supply chain management system'. Internal Report, Department of Industrial Engineering, University of Toronto.

Fugate, B., Sahin, F. \& Mentzer, J. T. 2006. 'Supply chain management coordination mechanisms', Journal of Business Logistics, 27(2): 129-162.

Garg, N. \& Koenemann, J. 1998. 'Faster and simpler algorithms for multicommodity flow and other fractional packing problems'. In Proceedings of 39th Annual Symposium on Foundations of Computer Scienc, Palo Alto, CA: New Delhi: Indian Inst. of Technol.

Goffin, K., Szwejczewski, M. \& New, C. 1997. 'Managing suppliers when fewer can mean more', International Journal of Physical Distribution and Logistics Management, 27(7): 422-436.

Goldberg, A. V., Tardos, E., \& Tarjan, R. E. 1990. 'Network flow algorithms, paths, flows, and VLSI-layout. London, England, Springer-Verlag, pp. 101-164.

Gomes da Silva, C., Figueira, B., Lisboa, J. \& Barman, S. 2004. 'An interactive decision support system for an aggregate production planning model based on multiple criteria mixed integer linear programming', Omega, 34(2):167-177.

Goold, M. \& Campbell, A. 1987. Strategies and styles. Oxford: Blackwell.

Goold, M. \& Quinn,J.J. 1993. Strategic control. London, England, FT Pitman Publishing.
Goold, M., Campbell, A. \& Alexander, M. 1994. Corporatelevel strategy: Creating value in the multi-business company. New York: Wiley.

Goold, M., Campbell A., \& Alexander, M. 1998. 'Corporate strategy and parenting theory- briefcase', Long Range Planning, 31(2): 308-314.

Grieger, M. 2003. 'Electronic marketplaces: A literature review and call for SCM research', European Journal of Operational Research, 144(2): 280-294.

Griesinger, D. 1990 'The human side of economic organization'. Academy of Management Review, 15(3): 478499.

Gupta, A. \& Maranas, C.D. 2003. 'Managing demand uncertainty in supply chain planning', Computers and Chemical Engineering, 27(8-9):1219-1227.

Gunnarsson, H. \& Rönnqvist, M. 2008. 'Solving a multiperiod supply chain problem for a pulp company using heuristics - An application to Södra Cell AB', International Journal of Production Economics, 116(1): 75-94.

Handfield, R. B., Ragatz, G. L., Petersen, K. J. \& Monczka, Robert M., 1999. 'Involving suppliers in new product development', California Management Review, 42(1):59-82.

Hill, C.W.L. 1990. 'Cooperation, opportunism and the invisible hands: Implications for transaction cost theory', Academy of Management Review, 15(3): 500-513.

Jayaraman, J. \& Pirkul, H. 2001. 'Planning and coordination of production and distribution facilities for multiple commodities', European Journal of Operational Research, 133(2): 394-408.

Kahn, J. 1987. 'Inventories and the volatility of production', The American Economic Review, 77(4):667-677.

Karmarkar, N. 1984. 'A new polynomial time algorithm for linear programming', Combinatorica, 4(4):373-395.

Kelle, P. \& Akbulut, A. 2005. 'The role of ERP tools in supply chain information sharing, cooperation and cost optimization', International Journal of Production Economics, 93-94(1): 41-52.

Koka B.R. \& Prescott, J.E. 2002. 'Strategic alliances as social capital: A multidimensional view', Strategic Management Journal, 23(9):795-806.

Langevin, A. \& Riopel, D. 2005. Logistics systems: Design and optimization. London, England, Springer.

Lee, Y. H., \& Kim, S. H. 2002. 'Production-distribution planning in supply chain considering capacity constraints', Computers and Industrial Engineering, 43: 169-190.

Lee, Y. H., Kim, S. H. \& Moon, S. H. 2002. 'Productiondistribution planning in supply chain using a hybrid approach', Production Planning and Control, 13: 35-46. 
Lee, H. L. \& Whang, S. 2000. 'Information sharing in a supply chain', International Journal of Manufacturing Technology and Management, 1(1): 79-93.

Lee, H. L., Padmanabhan, V. \& Whang, S. 1997a. 'The bullwhip effect in supply chains', Sloan Management Review, 38(3): 93-102.

Lee, H. L., Padmanabhan, V. \& Whang, S. 1997b. 'Information distortion in a supply chain: The bull whip effect', Management Science 43(4):546-558.

Lee, H. L., So, K. C. \& Tang, C. S. 2000. 'The value of information sharing in a two-level supply chain', Management Science, 46(5): 626-643.

Li, L. 2002. 'Information sharing in a supply chain with horizontal competition', Management Science, 48(9):11961212.

Li, X. \& Wang, Q. 2007. 'Coordination mechanism of supply chain systems', European Journal of Operational Research, 179(1):1-16.

Liu, Y., Zhang, Y. \& Zhao, Z. 2005.'The survey on supply chain coordination with contracts'. In Proceedings of the 7th ACM International Conference on Electronic Commerce,. New York, NY, October 2005, pp. 807-809.

Lorenzoni, G. \& Baden-Fuller, C. 1995. 'Creating a strategic center to manage a web of partners', California Management Review, 37(3): 146-163.

Lynch, R. 2006. Corporate strategy, $4^{\text {th }}$ Edition. London, England: Prentice Hall.

Meloa, M.T., Nickela, S. \& Da Gama, F. S. 2006. 'Dynamic multi-commodity capacitated facility location: A mathematical modeling framework for strategic supply chain planning', Computers and Operations Research, 33(1):181-208.

Metters, R. 1997. 'Quantifying the bullwhip effect in supply chains', Journal of Operations Management, 15(2): 89-100.

Monczka, R. M., Trent, R. J. \& Handfield, R. 1998. Purchasing and supply chain management. Cincinatti: South-Western College Publishing,

Ozdamar, L. \& Yazgac, T. 1999. 'A hierarchical planning approach for a production-distribution system', International Journal of Production Research, 37: 37593772 .

Porter, M. E. 1980. Competitive strategy. New York: The Free Press.

Powell, W.W. 1987. 'Hybrid organizational arrangements: New form or transitional development?', California Management Review, 30(1): 67-87.

Proff, H. 2006. 'Using consistent corporate strategies to maximize value addition by the parent organization of diversified company', International Journal of Learning and Intellectual Capital, 3(2):178-194.

Richardson, R. 1993. 'Parallel sourcing and supplier performance in the Japanese automobile industry', Strategic Management Journal, 14:339-350.

Sahin, F. \& E. Robinson, P. 2002. 'Flow coordination and information sharing in supply chains: Review, implications, and directions for future research', Decision Sciences, 33(4):505-536.

Sarimveis, H., Patrinos, P., Tarantilis, C.D. \& Kiranoudis, C.T. 2008. 'Dynamic modelling and control of supply chain systems: A review', Computers and Operations Research, 35: $3530-61$.

Sarmiento, A. M. \& Nagi, R. 1999. 'A review of integrated analysis of production-distribution systems', IIE Transactions, 31:1061-1074.

Sepehri, M. 1986. Just-in-time, not just in Japan - Case studies of American pioneers in JIT implementation. New Falls, Georgia: APICS Publications.

Shin, H. \& Benton, W.C. 2007. 'A quantity discount approach to supply chain coordination', European Journal of Operational Research, 80(2): 601-616.

Silver, E. A., Pyke, D. F. \& Peterson, R. 1998. Inventory management and production planning and scheduling. $3^{\text {rd }}$ Edition. Hoboken, NJ: Wiley.

Singh, R., Salam, A. F. \& Iyer, L. 2005. 'Agents in e-supply chains', Communications of the ACM, 48:109-115.

Strozzi, F. \& Zaldívar, J-M. 2008. 'Stability control in a supply chain: Total costs and bullwhip effect reduction', The Open Operational Research Journal, 2:51-59

Szwejczewski, M., Goffin, K., Lemke, F., Pfeiffer, R. \& Lohmuller, B. 2001. 'Supplier management in German manufacturing companies: An empirical investigation', International Journal of Physical Distribution \& Logistics Management, 31(5): 354-373.

Tayur, S., Ganeshan, R. \& Magazine, M. 1998. Quantitative models for supply chain management. $1^{\text {st }}$ Edition. London, England: Springer.

Terwiesch, C., Ren, T., Ho, H. \& Cohen, M. 2005. 'Forecast sharing in the semiconductor equipment supply chain', Management Science 51: 208-220.

Tsiakis, P. \& Papageorgiou, L. G. 2008. 'Optimal production allocation and distribution supply chain networks', International Journal of Production Economics, 111(2): $468-483$.

Wagner, S. M. 2000. 'A strategic approach to professional supplier management', National Productivity Review, 19(3):21-28. 
Young, D. \& Sutcliffe, B. 1990. 'Value gaps--who is right? -

The raiders, the market or the managers?, Long Range Planning, 23(4):20-34.

Zipkin, P. H. 2000. Foundations of inventory management. New York, NY: McGraw-Hill/Irwin. 


\section{APPENDIX A: Description of Locally Optimum Behavior}

Selfish/competitive members in a traditional supply chain place orders based on their locally optimum utility rather than complying with the globally optimum solution. If this is the case, each competitive member tries to find available sources with the lowest cost until its demand is fulfilled.

A supply chain is modeled using the concept of flow networks. Assume v is a destination member to receive flow (product, component or raw materials) from a source node $\mathrm{t}$ where an $\operatorname{arc}(\mathrm{t}, \mathrm{v})$ exists in the corresponding graph. Consider $\mathrm{S}$ as an array of information about all potential sources for $\mathrm{v}$ to fulfill its demand. Therefore, $S_{t}$ ( $t$ th element of the array) is an ordered pair $(\mathrm{o}(\mathrm{t}, \mathrm{v}), \mathrm{c}(\mathrm{t}, \mathrm{v}))$. o(t, v) indicates cost of flow in the arc $(\mathrm{t}, \mathrm{v})$, and $\mathrm{c}(\mathrm{t}, \mathrm{v})$ shows capacity of this arc. In fact, the member $\mathrm{v}$ forms array $\mathrm{S}$ using the information received from its potential source nodes. The following pseudo-code describes the competitive behavior of the destination member $\mathrm{v}$ :

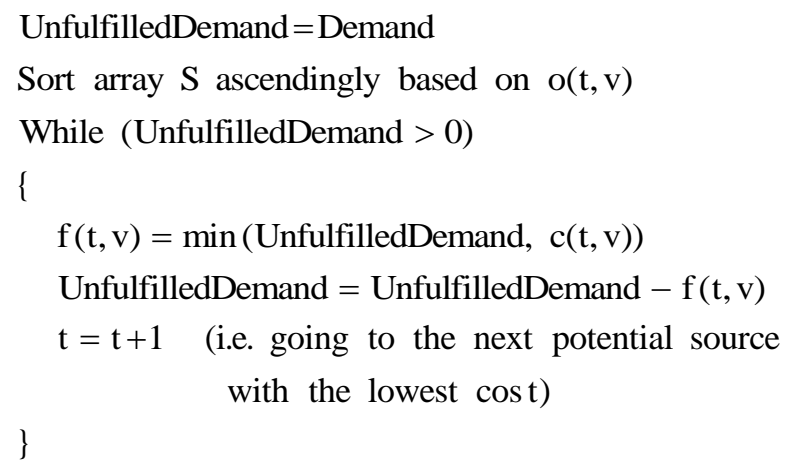

Based on the pseudo-code above, each member of supply chain, to source its demand, simply searches for available sources with the lowest costs. It is assumed that members of each stage do their respective sourcing sequentially with a random order. For example, if there are three members R1, R2 and R3 in the retailer stage, a random sequence can imply that first R1 do its sourcing followed by R2, and finally R3 tries finding its sources based on what is available. Finally, cost of the supply chain will be sum of the costs of all members of the supply chain. 